\title{
Editorial
}

\section{EUROSURVEILLANCE COMES OF AGE AND MOVES TO ECDC}

\author{
Hélène Therre ${ }^{1}$, Jean-Claude Desenclos ${ }^{2 *}$, Elizabeth Hoile ${ }^{3}$, Noel Gill ${ }^{4 *}$, and Jean-Baptiste Brunet ${ }^{\text {* }}$
}

1. Eurosurveillance, Institut de Veille Sanitaire, Saint-Maurice, France

2. Infectious Diseases Department, Institut de Veille Sanitaire, Saint-Maurice, France

3. Eurosurveillance, Health Protection Agency Centre for Infections, London, United Kingdom

4. Health Protection Agency Centre for Infections, London, United Kingdom

5. French Permanent Representation to European Union, Brussels, Belgium

Eurosurveillance was created in 1995 to support exchange and dissemination of authoritative scientific information within the part of public health community involved in the field of infectious disease surveillance and control, at a time when European surveillance networks were at an early stage of growth. Now part of a large network, the publication is entering a new stage: the editorial function will now be hosted at the European Centre for Disease Prevention and Control (ECDC) in Stockholm. This will strengthen the platform for the next stage in Eurosurveillance's development as the major home of peer-reviewed European information on infectious disease surveillance and control.

It was in the early 1990s that the feasibility of a Europe-wide disease surveillance through a network of experts was first explored. As stated in 1992 in The Lancet '... one response to the AIDS epidemic has been the establishment of a European network for monitoring this disease. Experience has proved that effective international surveillance is feasible in Europe...' [1]. This network, now known as EuroHIV, was the first European surveillance network for a communicable disease, and had been set up in 1984 under the umbrella of the World Health Organization Regional Office for Europe and funded by the European Commission's Directorate-General for Research, as the European Centre for the Epidemiological Surveillance of AIDS in Paris.

Many other networks were later implemented for priority diseases such as legionellosis (EWGLI), salmonellosis (Salm-net, which became Enter-net in 1998), influenza (EISS) and tuberculosis (EuroTB), [2-6]. Most of these, hosted by one or two national public health institutes, were funded by the European Commission's Directorate-General for Public Health (now DG Sanco) under a series of consecutive public health $(\mathrm{PH})$ programmes, and the DSN concept was born. This acronym (which stands both for 'Disease Specific Network' and 'Designated Scientific Network') was later applied to a greater number of networks, some of which, such as EARSS (for antimicrobial resistance) [7], were not specific to one particular disease.

Eurosurveillance's ambition was to play a communication role that would complement the training and human resources role played by another successful European programme, the European Programme for Intervention Epidemiology Training, EPIET [8]. The challenge was to become part of the infrastructure for the growing European infectious disease and public health surveillance community, while filling gaps left by existing scientific journals and academic institutions whose interest in the topic was somewhat weak. The growth of Eurosurveillance relied heavily on the pioneers of these growing surveillance networks, the support of the European Commission through the $\mathrm{PH}$ programme and the work of the editorial board, made up of 'national gatekeepers' from each of the European national public health institutes. These national gatekeepers who served as editorial advisors to Eurosurveillance were frequently the editors of the national epidemiological bulletins.

Eurosurveillance is one of the numerous pieces of a patiently assembled puzzle that benefited from growing political interest and recognition. With the 2119/98/EC Decision of the EU Parliament and Council on the network for infectious disease surveillance [9], the 2000/57 Commission Decision on the early warning and response system [10], and in May 2005 [11], the creation of the ECDC, the goal of a European service for public health surveillance and control of infectious diseases has become a reality.

Within the past 10 years, many public health events have continued to change public and political perception of infectious disease threats. These include bioterrorism threats following 9/11, the anthrax events in the United States, the emergence of a new pathogen with the SARS outbreak, the increasing dissemination antimicrobialresistant microorganisms, the increased concern about an influenza pandemic, and the concomitant need for pandemic preparedness by Member States. These changes may explain why the concept of a 'physical' European centre, which had been discarded in the early 1990s for the preferred concept of a virtual centre (a network or a service), became a widely recognised necessity [12]. In 2002, David Byrne, at the time Europe's Commissioner for Health and Consumer Protection, was campaigning at the European Health Forum for the creation of a European centre which 'will bring together the expertise in Member States and will act as a reference and coordination point both in routine and crises situations' [13].

The coming together of Eurosurveillance and ECDC is a logical consolidation of the international infrastructure within the European Union to combat infectious diseases.

Eurosurveillance is now coming of age and entering adulthood. It is moving to a new home and will face new challenges. In the name of all its numerous parents, let us say that we are very proud.

*Editorial note: Jean-Claude Desenclos, Noel Gill, and JeanBaptiste Brunet were among the pioneers of the project. 


\section{Acknowledgements}

We wish to thank all the members of the French and English editorial team of Eurosurveillance from the Institut de Veille Sanitaire (InVS) and the Health Protection Agency (HPA, formerly the Public Health Laboratory Service), and in particular, Anneli Goldschmidt and Farida Mihoub, who participated in Eurosurveillance since the dummy issue in 1995 and who have greatly contributed to making Eurosurveillance a multilingual resource; the numerous editors between 1995 and 2007 namely Hélène Therre, Mina Vilayleck, Françoise Reboul-Salze, Stuart Handysides, Caroline Akehurst, Birte Twisselmann, Fiona Reid, Elizabeth Hoile, Laura Pritchard and Candice Pettifer. Invaluable IT support was provided by Christian Leroy, Patricia Gless, Thamin Abdesselam, Chris Walker, and Daniel Dubois. Countless members of staff at the InVS and the HPA have also lent their support, technical expertise and enthusiasm to the project.

We wish to thank all the editorial board partners, without whom Eurosurveillance's authoritative European voice would never have seen the light; and the associate editors, namely Henriette de Valk, Richard Pebody, Norman Noah, Stefania Salmaso, who contributed to Eurosurveillance development and, with the many reviewers, guaranteed its scientific quality.

We thank also DG-SANCO and its representative Germain Thinus. DG-SANCO maintained project funding from the beginning and contributed to making Eurosurveillance an open access and free journal.

We are also very grateful for the full and continuous institutional support of InVS (France) and the HPA (UK).

Finally, we wish to thank all those who were involved early on in the creation of Eurosurveillance. These include Elisabeth Bouvet and Jacques Drücker (France), Maurice Robert (European Commission), Chris Bartlett (UK), Meinrad Koch (Germany) and we also extend our thanks to any other pioneers whom we may have unintentionally missed in this list.

\section{References}

1. Desenclos JC, Bijkerk H, Huisman J. Variations in national infectious diseases surveillance in Europe. Lancet. 1993;341(8851):1003-6.

2. Hutchinson EJ, Joseph CA, Bartlett CLR on behalf of the European Working Group for Legionella Infections. EWGLI: a European surveillance scheme for travel associated legionnaire's disease. Euro Surveill. 1996;1(5):37-39. Available from: http://www.eurosurveillance.org/em/v01 n05/0105-223.asp

3. Antoine $D$, Schwoebel $V$, Veen $J$, Raviglione $M$, Rieder $\mathrm{HL}$ and the national coordinators for tuberculosis surveillance in 50 countries of the WHO European Region. Surveillance of tuberculosis in the WHO European Region 1995-1996. Euro Surveill. 1998;3(11):103-7. Available from: http://www.eurosurveillance.org/em/v03n11/0311-221.asp

4. Fisher I. Salm-Net: a network for human salmonella surveillance in Europe. Euro Surveill. 1995;0(0):7-8. Available from: http://www.eurosurveillance. org/em/v00n00/0000-225.asp

5. Zambon M. Sentinel surveillance of influenza in Europe 1997-1998. Euro Surveill 1998;3(3):29-31. Available from: http://www.eurosurveillance.org/ em/v03n03/0303-224.asp

6. Fisher I The Enter-net international surveillance. network - how it works. Euro Surveill. 1999;4(5):52-5. Available from: http://www.eurosurveillance. org/em/v04n05/v04n05.pdf

7. Veldhuijzen I. European Antimicrobial Resistance Surveillance System (EARSS): a healthy newborn . Eurosurveillance Weekly [1812-075X]. 1999 Dec 9;12(50) 991209. Available from: http://www.eurosurveillance.org/ ew/1999/991209.asp\#1

8. Moren A, Rowland M, Van Loock F, Giesecke J. The European Programme for Intervention Epidemiology Training. Euro Surveill. 1996;1(4):30-1. Available from: http://www.eurosurveillance.org/em/v01n04/0104-225.asp

9. Decision no 2119/98/EC of the European Parliament and of the Council of 24 September 1998. Setting up a network for the epidemiological surveillance and control of communicable diseases in the community. Official Journal of the European Communities 1998; L 268/1: 3 October Official Journal of the European Communities 1998; L 268/1: 3 October
1998. Available from: http://europa.eu.int/eur-lex/pri/en/oj/dat/1998/l_268/ l_26819981003en00010006.pdf

10. Commission Decision 2000/57/EC of 22.12.1999 on the early warning system for the prevention and control of communicable diseases. Official Journal L 21, 6.1.2000. Available from: http://europa.eu.int/eur-lex/pri/en/oj/dat/2000/ l_021/l_02120000126en00320035.pdf

11. Haigh R, Kokki M. Perspectives for a European Centre for Disease Prevention and Control. Euro Surveill. 2004;9(10):3-4. Available from: http://www. eurosurveillance.org/em/v09n10/0910-222.asp

12. Van Loock F, Gill ON, Wallyn S, Nicoll A, Desenclos JC, Leinikki P. Roles and functions of a European Union Public Health Centre for Communicable Diseases and other threats to health. Euro Surveill. 2002;7(5):78-84. Available from: http://www.eurosurveillance.org/em/v07n05/0705-225.asp

13. Byrne D. Future priorities in the EU policies. Speech/02/426 to the European Health Forum on "Common challenge for health and care". Gastein. September 2002

Citation: Therre H, Desenclos J, Hoile E, Gill N, Brunet J. Eurosurveillance comes of age and moves to ECDC. Euro Surveill 2007;12(2)[Epub ahead of print]. Available online: http://www.eurosurveillance.org/em/v12n02/1202-221.asp 